\title{
Sub-Micron Fracture Mechanism in Silica-Based Glasses Activated by Permanent Densification from High-Strain Loading ${ }^{1,2}$
}

Andrew A. Wereszczak, ${ }^{*} 3$ Shirley B. Waters, and Randy J. Parten

Materials Science and Technology Division

Oak Ridge National Laboratory

Oak Ridge, TN 37831, USA

* Joint Faculty Professor

Department of Materials Science and Engineering

University of Tennessee, Knoxville, TN 37996, USA

L. David Pye

Dean and Professor of Glass Science, Emeritus

The New York State College of Ceramics at Alfred University

Little Falls, NY 13365

1 This research was performed at the Oak Ridge National Laboratory (ORNL) and sponsored by Purdue University under the Material Science and Technology Division, Work-for-Others (WFO) Program, IAN: 14B658801, and DOE agreement: NFE-10-03121, with the U.S. Department of Energy.

Additional support provided by the US Army Research Laboratory through Contract W911NF-14-20015 at the University of Tennessee.

2 Notice: This manuscript has been authored by UT-Battelle, LLC under Contract No. DE-AC0500OR22725 with the U.S. Department of Energy. The United States Government retains and the publisher, by accepting the article for publication, acknowledges that the United States Government retains a non-exclusive, paid-up, irrevocable, world-wide license to publish or reproduce the published form of this manuscript, or allow others to do so, for United States Government purposes. The Department of Energy will provide public access to these results of federally sponsored research in accordance with the DOE Public Access Plan (http://energy.gov/downloads/doe-public-access-plan).

3 Corresponding author, wereszczakaa@ornl.gov. 


\begin{abstract}
Several silica-based glasses were fractured at high strain energy via drop-weight testing on small specimens. A cylindrical specimen geometry was chosen to promote initially simple, axisymmetric, and uniform compressive loading. The imposed uniaxial compressive strain at impact was sufficiently high to qualitatively cause permanent densification. Produced fragments were collected for postmortem and a fraction of them, for all the silica-based glasses, consistently had distinct sub-micron-sized fractures $(\sim 300-1000 \mathrm{~nm})$, designated here as "microkernels", on their surfaces. They would most often appear as a sub-micron pore on the fragment - apparently if the microkernel had popped out as a consequence of the local crack plane running through it, tensile-strain release, and the associated formation of the fragment it was on. No fractographic evidence was found to show the microkernels were associated with local failure initiation. However, their positioning and habit sometimes suggested they were associated with localized crack branching and that they could have influenced secondary fracturing that occurred during overall crushing and comminution and associated fragment size and shape creation. The size range of these microkernels is much too small to affect structural flexure strength of these glasses for most applications but are of a size and concentration that may affect their ballistic, shock, crush, and comminution responses when permanent densification is concomitantly occurring.
\end{abstract}

\title{
Keywords:
}

Silica-based glasses, high-strain-energy fracture, densification, fragmentation, microkernels. 


\section{Introduction}

The mechanical response of glasses or ceramics used in armor systems from a ballistic impact is a complex consequence of many independent properties and geometrical parameters of both the target and projectile materials. That response in the target materials is influenced by fracture and plastic-like deformation processes that are functions of time and continuallychanging, high-magnitudes of multiaxial stress states caused by the projectile's impact energy and any penetration. Shock propagation into the target, and its potentially-induced damage, is occurring concurrent with that project-target interaction.

Primary and post-primary fracture in brittle materials that occurs during either simple uniaxial or multiaxial loading are consequences of the imposition of sufficiently high First Principal tensile stresses and those tensile stresses exceeding some definition of tensile strength

for that material. For predicting ballistic response of armor systems containing glasses or ceramics, modelers utilize an inputted tensile strength that is an important parameter for accounting for fracture processes within those brittle materials.

In a recently completed study by one of the authors [1], the internally initiated fracture of a borosilicate glass, caused by shock (a localized, yet high-strain-energy event), was examined along with the modeled estimation of the tensile stress associated with its formation. An image of that internally generated crack is shown in Fig. 1. That estimated tensile failure stress, assuming a material elastic response, was large - approximately $1.2 \mathrm{GPa}$. With the exception of some strengthened glasses, that 1.2 GPa failure stress is nearly an order of magnitude higher than the (tensile) failure stress of almost all commonly used silicate glasses fractured in bending. 


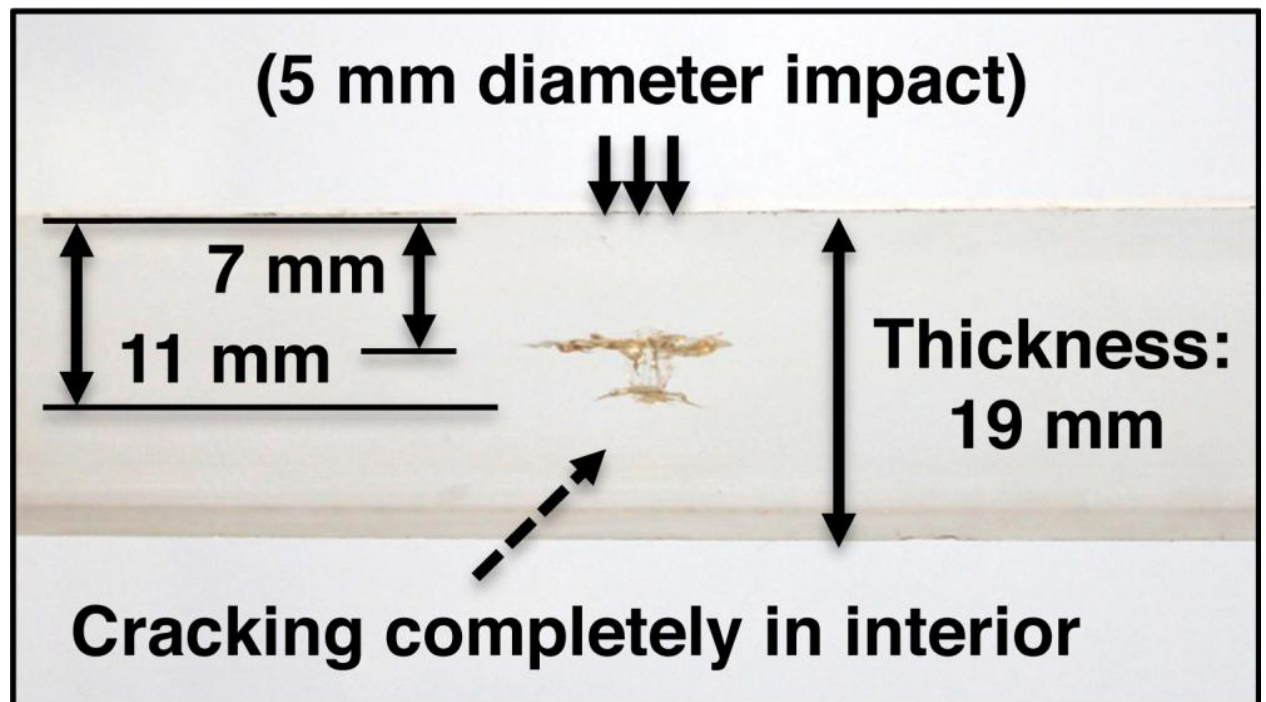

Figure 1. Generated internal cracks in Borofloat glass resulting from laser shock.

It follows that the estimated (internal) flaw associated with a 1.2-GPa-failure in glass must be very small. The calculated, quasi-statically-generated Griffith flaw size [2] is $~ 600 \mathrm{~nm}$ using that tensile failure stress value, a reasonable fracture toughness of borosilicate glass of 0.75 $\mathrm{MPa} \sqrt{ } \mathrm{m}$, and a stress intensity shape factor of 1.13 for a volume-located circular flaw [3]. Its size will be smaller if a (more likely) non-circular-shaped flaw was the tensile-stress-limiter with a lower bound of $\sim 250 \mathrm{~nm}$ [3]. In contrast, the size of a half-penny surface crack limiting the same glass to $100 \mathrm{MPa}$ in bending (which is a relatively high bend strength for non-strengthened silica-based glasses) would be two orders of magnitude larger $(\sim 70,000 \mathrm{~nm})$.

The fracture morphology of the 7-mm-deep lateral crack in Fig. 1 produced several interesting observations. It was carefully refractured to enable microscopy to be conducted directly and orthogonally on that lateral crack system. Several scanning electron microscopy (SEM) images of such are shown in Fig. 2. An unexpected tempered-glass-like fracture habit existed over approximately a 1-mm-diameter, and is shown in Fig. 2(a). There were multiple locations of failure initiation. The shock pulse was only a few nanoseconds in duration, and for a terminal crack propagation speed of $\sim 1900 \mathrm{~m} / \mathrm{s}$, a crack would propagate about $10 \mu \mathrm{m}$ in that time. Therefore there is a likelihood that multiple failure initiation sites could have occurred. Two observations are highlighted and shown in Figs. 2(b)-(d). Several discrete mirrors were 
evident in the microstructure shown in Fig. 2(a)-(b). An example of one shown in Fig. 2(c) with a calculation of the local stress using the estimated mirror radius size [4]. Its stress was estimated to be $1.7 \mathrm{GPa}$ which is high like what was estimated from modeled tensile stress [1], but other measurements calculated a range of stresses down to approximately $900 \mathrm{MPa}$. The flaw at the center of the mirror radius in Fig. 2(c) could not be identified; however, its Griffith flaw size associated with $1.7 \mathrm{GPa}$ is a few hundred nanometers. An example of a seam of localized heterogeneities, designed here as "microkernels" and shown in Fig. 2(d), were also observed within this microfracture region. Their presence appears to be associated with the front of a localized crack propagation bifurcation. Their size, perhaps not coincidentally, is equivalent to the approximated Griffith flaw size calculated for the example in Fig. 2(c).
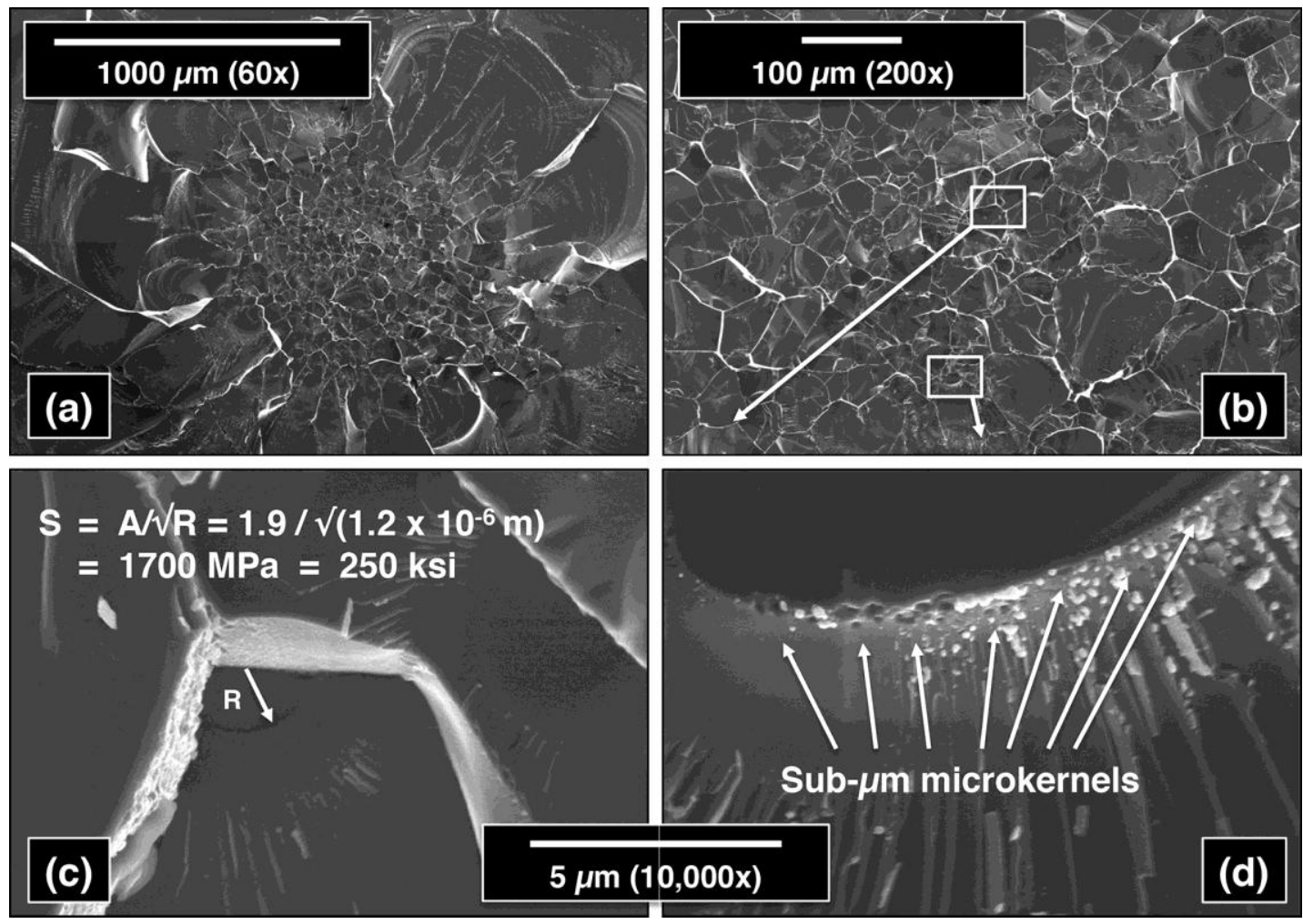

Figure 2. Fracture morphology of the 7-mm-deep lateral crack shown in Fig. 1. Low magnifications $(a)$ and $(b)$ with zoomed in region showing $(c)$ one of the many fracture mirrors, and (d) a seam of microkernels located where a local crack deflection had occurred. Shock wave direction was perpendicular to this surface. 
The initial motivation of the present study was to determine if these microkernels could be exposed for further examination through (easier-to-conduct and less expensive) quasi-static fracture produced at high-strain energies. Several silica-based glasses were fractured at room temperature via drop weight testing onto small cylindrical specimens. The estimated imposed compressive strain at impact exceeded 1\%. The surfaces of collected fragments were then microscopically examined. Like what was shown in Fig. 2, a fraction of the fragments of all the silica-based glasses had distinct sub-micron-sized microkernels on their surfaces. However, the fragments were found to have undergone permanent densification, and a qualitative correlation was identified between the onset of that permanent densification (caused by high strain loading) and the formation of these microkernels. 


\section{Materials and Methods}

A variety of commercially available silica-based glasses were tested. They included high-purity fused quartz and fused silica, borosilicates, and soda-lime silicates. The same glass, whose shock testing was discussed in Figs. 1-2, was included. Additional materials and test temperatures were added to the initial test matrix to improve overall understanding of the fracture processes at high strain energies. Most of the silicates were in tile form and cylinders (6.35-mm nominal diameter) were core-drilled out of those while disks of other materials were purchased and they were tested as-is. The chosen diameter was deemed to be a good compromise between being able to generate relatively high compressive strain at impact while also producing a sufficient volume of fragments for analysis. An example of a core-drilled sample is shown in Fig. 3(a). The samples were not radially confined during impact testing.

A heavy mass was dropped on the cylinders or disks to apply the initial high-strain energy. The heavy mass was a tungsten alloy with a density of $18 \mathrm{~g} / \mathrm{cm}^{3}$ and had cylindrical geometry with a diameter of $80.6 \mathrm{~mm}$ and a length of $190 \mathrm{~mm}$. It had a mass of $17.5 \mathrm{~kg}$ and its speed was calculated to be approximately $4 \mathrm{~m} / \mathrm{s}$ when dropped from a height of approximately 0.9 meters; that produced a calculated kinetic energy of approximately $150 \mathrm{~J}( \pm 10 \%)$ at impact. The samples were uniaxially impacted and the entire thickness of the samples was subjected to a (initially) high and uniform compressive strain estimated to exceed 1\%. A tube was used to guide the large cylinder's drop onto the positioned sample and was fastened at the bottom to constrain the weight and test fragments after the event. The tube, drop-weight, and foundation were thoroughly cleaned after each test to avoid the introduction of contamination for later tests. An example of the test setup is shown in Fig. 3(b).

The generated fragments were collected after each test, and those passing through a 230mesh $(63 \mu \mathrm{m})$ sieve were ultrasonically cleaned in acetone for 10 minutes and readied for fieldemission FE-SEM examination. A brand new sieve was used for each powder to avoid contamination. Motivation behind examining particles smaller than this size is discussed later. An example of a sieved powder is shown in Figs. 3(c)-(d). 
The sub-63- $\mu \mathrm{m}$ fragments were examined with FE-SEM (Hitachi Model S-4800, Tokyo, Japan) in a manner that enabled equitable judgment of microkernel concentration among the test materials. Sputter coating of the fragments initially was not used so not to introduce misleading artifacts on the fragment fracture surfaces; however, the coating was shown to not create artifacts that could cause false positives, so it ended up being used so to avoid beam charging and allow for higher magnification imaging. Many fragments were examined over the course of at least 50 minutes, and almost all materials were reexamined on at least two occasions. This resulted in the inspection of at least 50 randomly selected fragments per test material.

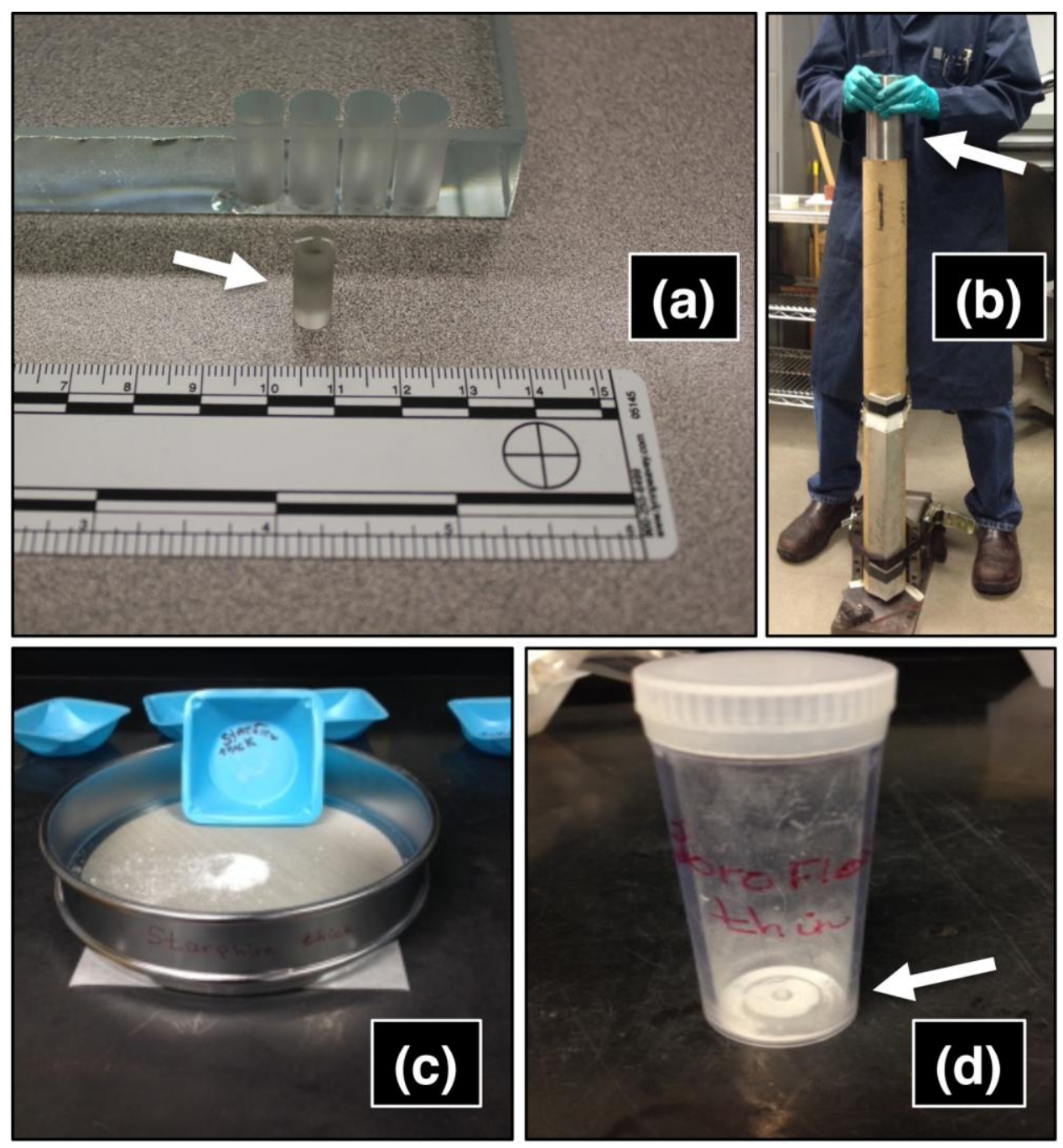

Figure 3. Examples of (a) core-drilled sample, (b) drop-weight test setup with arrow pointing toward 17.5-kg mass prior to its release, (c) 230 mesh or $63 \mu \mathrm{m}$ sieving, and (d) passed-through powder that would be examined in the FE-SEM. 


\section{Results}

A fraction of the fragments of all the silica-based glasses had distinct sub-micron-sized fractures with microkernels on their surfaces. Their concentration appeared to be material dependent. They ranged in size from $~ 300-1000 \mathrm{~nm}$. A summary of the evaluated materials and estimations of relative concentrations of the microkernels are shown in Table I.

Examples of the sub-micron microfractures for Borofloat borosilicate (two thicknesses), Starphire soda-lime silicate (two thicknesses), fused quartz, fused silica, BK7 borosilicate, and Gorilla Glass are shown in Figs. 4-7. Both Borofloat and Starphire are float glasses, and interest existed to see if thickness had a correlation with sub-micron microfracture concentration; any differences were not observable. Fused quartz was made by a melt-casting process and the fused silica was made by a hydrolysis process (and therefore had a higher water content than the fused quartz); sub-micron microfractures existed on them as well. BK7 borosilicate glass, an opticalgrade of glass (i.e., processed in a manner to promote maximum homogeneity), also had submicron microfractures but with a low concentration. Gorilla Glass, along with the Borofloat, had the highest concentration of the sub-micron microfractures.

Additional materials were tested to further interpret the sub-micron microfractures of the above silica-based glasses. Synthetic alpha-quartz also had sub-micron microfractures and an example of them is shown in Fig. 8. Attention was then also devoted to the testing of nonsilicate non-polycrystalline materials, so single crystal magnesium fluoride and sapphire were high-strain-energy tested. Examples of these two materials are shown in Figs. 9 and no submicron microfractures were observed. 
Table I. Summary of impacted materials and analysis of their fragments.

\begin{tabular}{|c|c|c|c|}
\hline $\begin{array}{c}\text { Material } \\
\text { (composition) } \\
\text { Manufacturer or Supplier }\end{array}$ & $\begin{array}{l}\text { Thickness of } \\
\text { Impacted } \\
\text { Specimen } \\
\text { (mm) }\end{array}$ & $\begin{array}{c}\text { Microkernels or } \\
\text { micropores? }\end{array}$ & $\begin{array}{c}\text { Relative } \\
\text { Concentration } \\
\text { (1: low, 3: high) }\end{array}$ \\
\hline $\begin{array}{c}\text { BOROFLOAT } \\
\text { (borosilicate) } \\
\text { SCHOTT GLASS } \\
\end{array}$ & 3 & Yes & 3 \\
\hline BOROFLOAT & 19 & Yes & 3 \\
\hline $\begin{array}{c}\text { STARPHIRE } \\
\text { (soda lime silicate) } \\
\text { PPG } \\
\end{array}$ & 3 & Yes & 1 \\
\hline STARPHIRE & 19 & Yes & 1 \\
\hline $\begin{array}{c}\text { Fused Quartz } \\
\text { (high purity vitreous silica } \\
\text { made by melting) } \\
\text { Quartz Scientific } \\
\end{array}$ & 6.35 & Yes & 2 \\
\hline $\begin{array}{c}\text { Fused Silica } \\
\text { (high purity vitreous silica } \\
\text { made by hydrolysis) } \\
\text { Corning }\end{array}$ & 10 & Yes & 2 \\
\hline $\begin{array}{c}\text { BK7 } \\
\text { (borosilicate) } \\
\text { SCHOTT GLASS }\end{array}$ & 12 & Yes & 1 \\
\hline $\begin{array}{c}\text { Gorilla Glass } \\
\text { (aluminosilicate) } \\
\text { Corning/Edmund Optics }\end{array}$ & $3.3 *$ & Yes & 3 \\
\hline $\begin{array}{c}\text { alpha-Quartz } \\
\text { (synthetic single crystal) } \\
\text { Boston Scientific } \\
\end{array}$ & 17 & Yes & 2 \\
\hline $\begin{array}{c}\text { Magnesium Fluoride } \\
\text { (synthetic single crystal) } \\
\text { Edmund Optics } \\
\end{array}$ & $3 *$ & No & \\
\hline $\begin{array}{c}\text { Sapphire } \\
\text { (synthetic single crystal) } \\
\text { Edmund Optics }\end{array}$ & 3.18 & No & \\
\hline $\begin{array}{c}\text { BOROFLOAT } \\
\text { Impacted while hot } * *\end{array}$ & 19 & $\begin{array}{c}\text { Yes: } \\
\text { More still-adhered } \\
\text { microkernels than } \\
25^{\circ} \mathrm{C} \text { testing } \\
\end{array}$ & 3 \\
\hline $\begin{array}{c}\text { STARPHIRE } \\
\text { Impacted while hot } * *\end{array}$ & 19 & Yes & 1 \\
\hline
\end{tabular}

* Three disks were stacked and impacted together to increase the volume of fragments. Total thickness indicated.

** Sample heated to $600^{\circ} \mathrm{C}$ then impacted at room temperature in less than 30 seconds. The samples' average temperature at impact was unknown but estimated to be greater than $400^{\circ} \mathrm{C}$. 


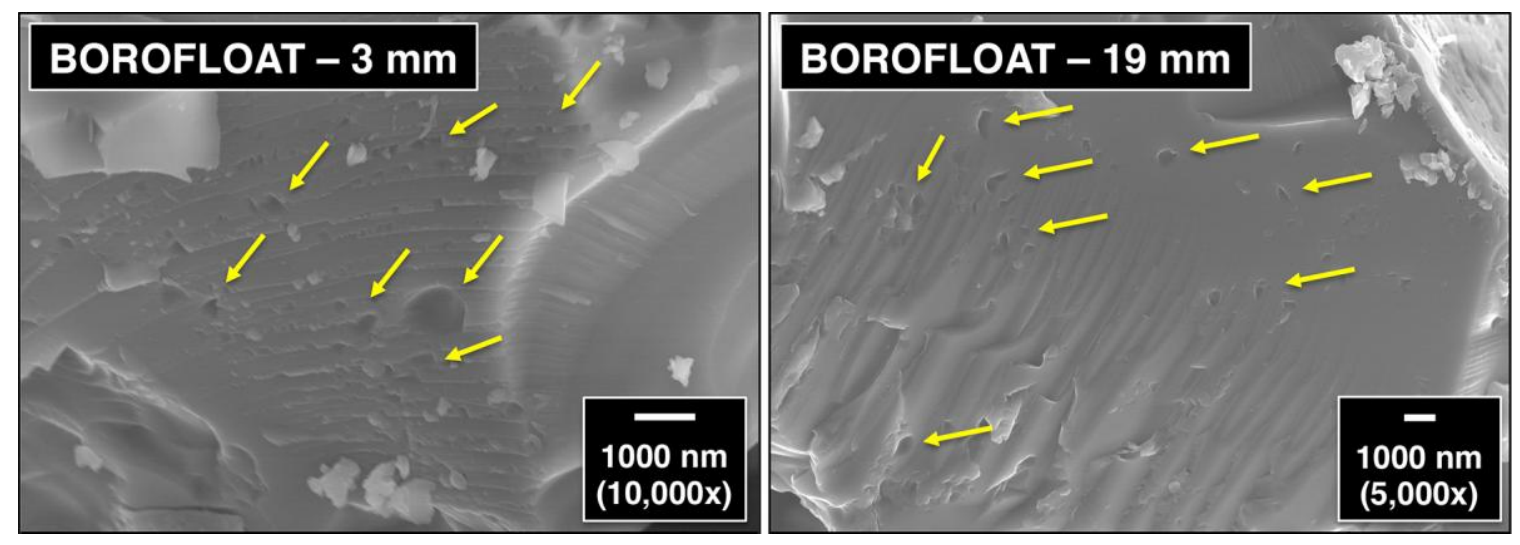

Figure 4. Examples of sub-micron microfractures on the surfaces of Borofloat fragments from two different thicknesses of glass.
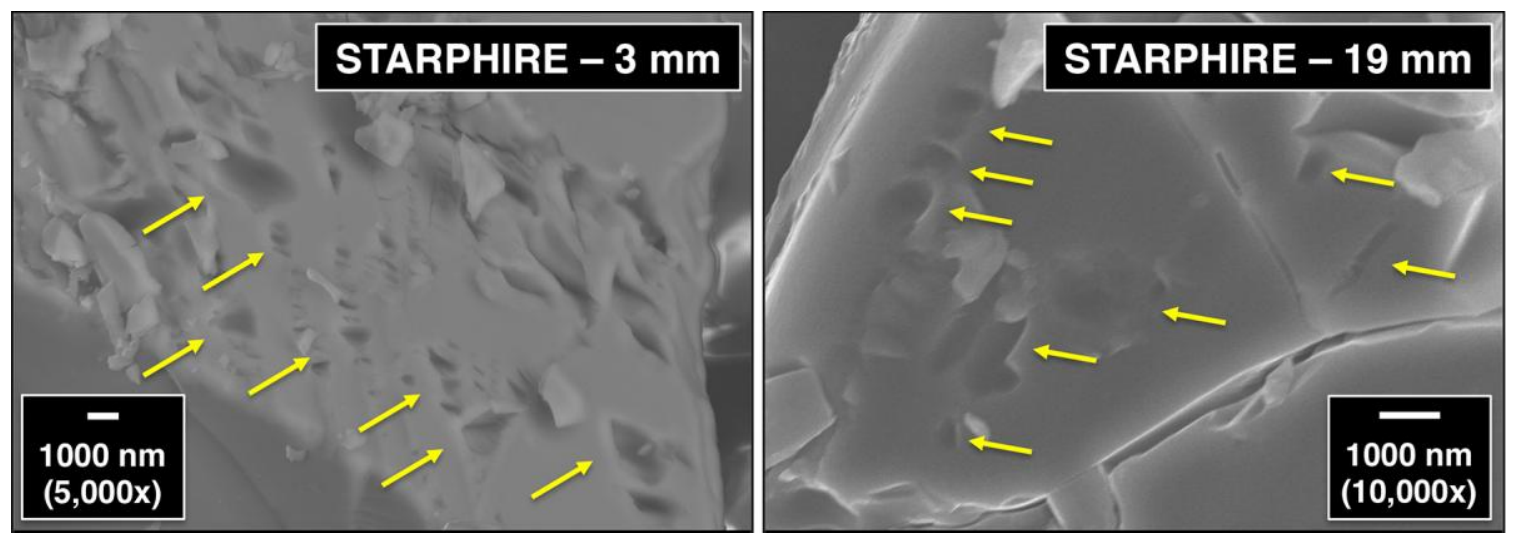

Figure 5. Examples of sub-micron microfractures on the surfaces of Starphire fragments from two different thicknesses of glass. 


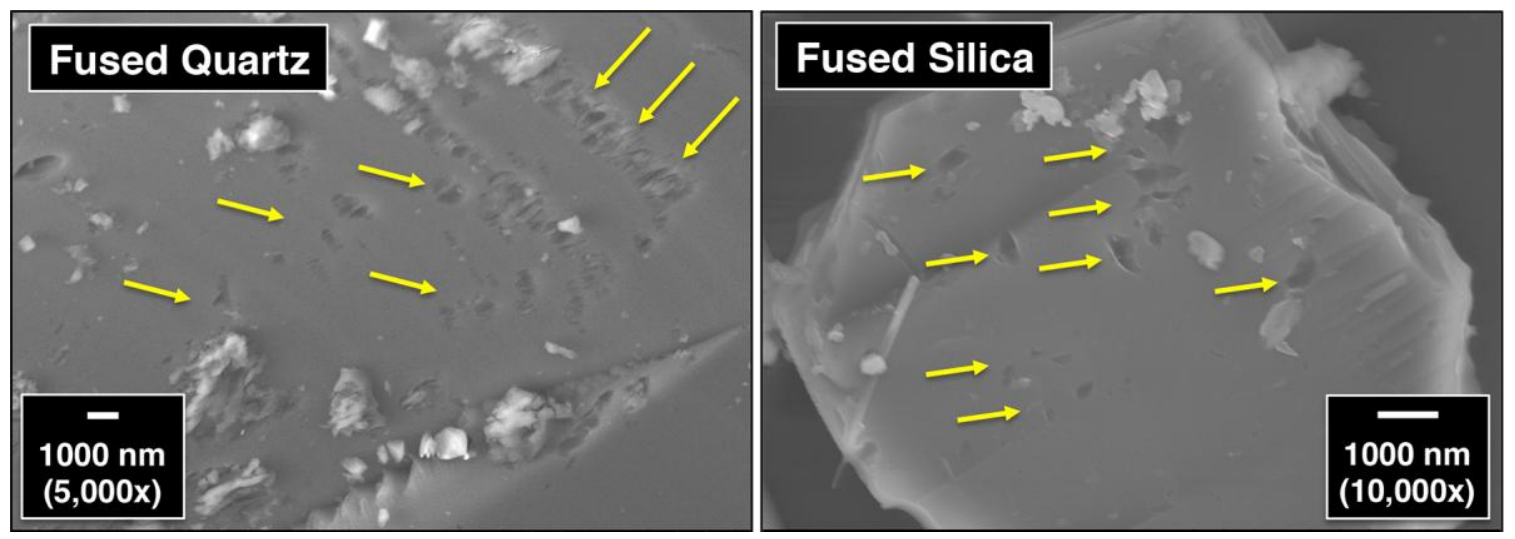

Figure 6. Examples of sub-micron microfractures on the surfaces of fragments from high-purity fused quartz and fused silica.

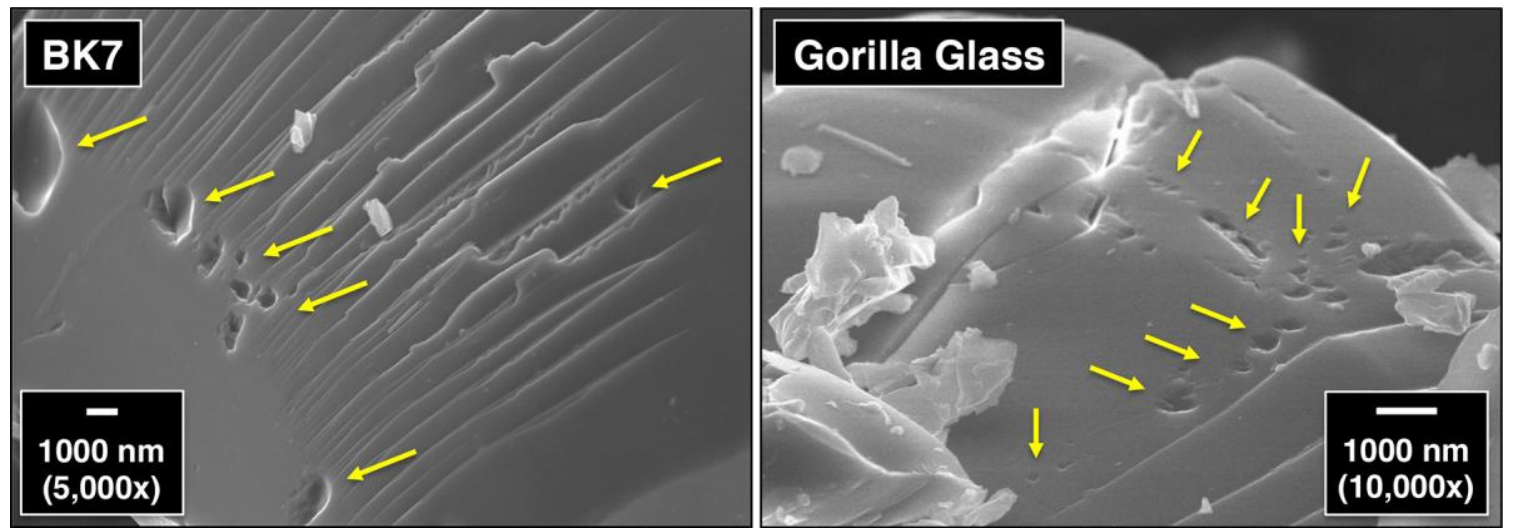

Figure 7. Examples of sub-micron microfractures on the surfaces of fragments from BK7 borosilicate and Gorilla Glass. 


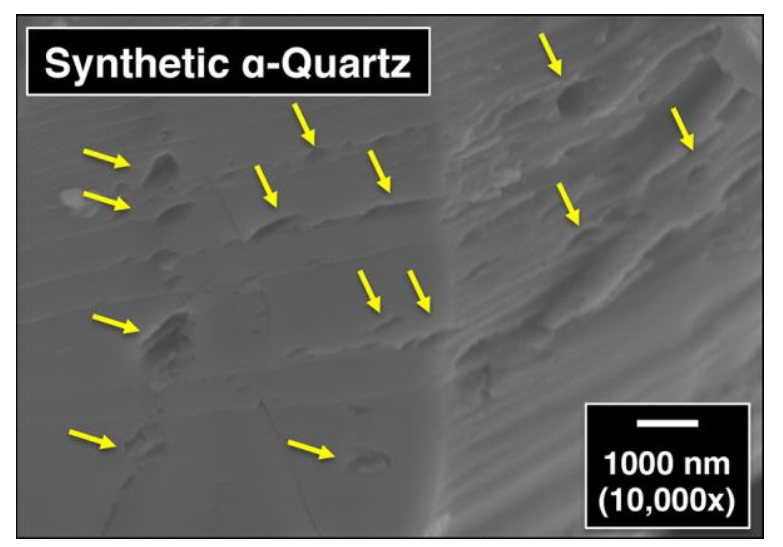

Figure 8. Examples of sub-micron microfractures on the surfaces of fragments from synthetic and crystalline alpha-quartz.

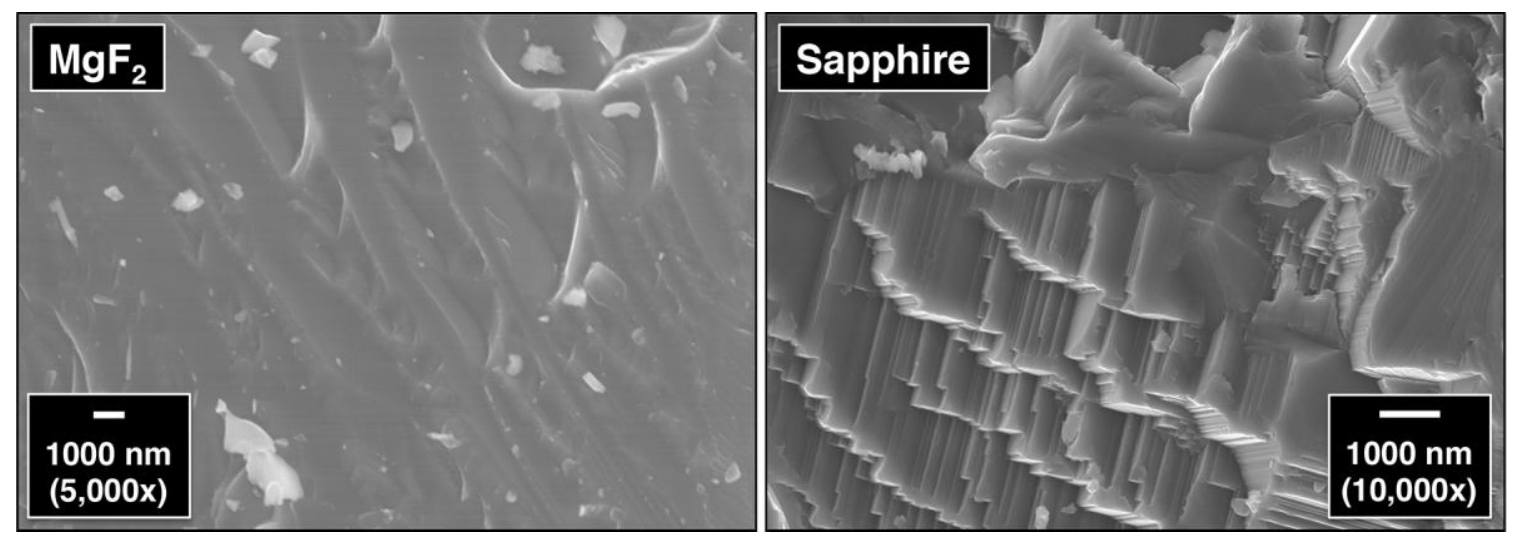

Figure 9. No sub-micron microfractures were identified on the surfaces of fragments from single crystal magnesium fluoride and single crystal sapphire. 
Extra samples of the (thick) Borofloat and (thick) Starphire were preheated in a furnace at $600^{\circ} \mathrm{C}$ and then rapidly (in less than 30 seconds) transferred for drop-weight impact testing. The motivation for this was to see if a potential lower viscosity of the glass would affect the microfracturing. The sample temperatures were unknown at impact; however, they were believed to be at several hundred degrees Celsius. The postmortem analysis of the fragments from this high-temperature testing was indeed informative because it influenced the authors into reconsidering these sub-micron microfractures as microkernels, and not indigenous micro-pores that were initially, and almost exclusively, observed. Examples of these microkernels are shown in Fig. 10. They inspired revisitation of earlier imaging and such microkernels were indeed evident in (room-temperature-tested) fused quartz and fused silica - also shown in Fig. 10, and they were sometimes observed as an agglomerated pile after ultrasonic cleaning (Fig. 11).

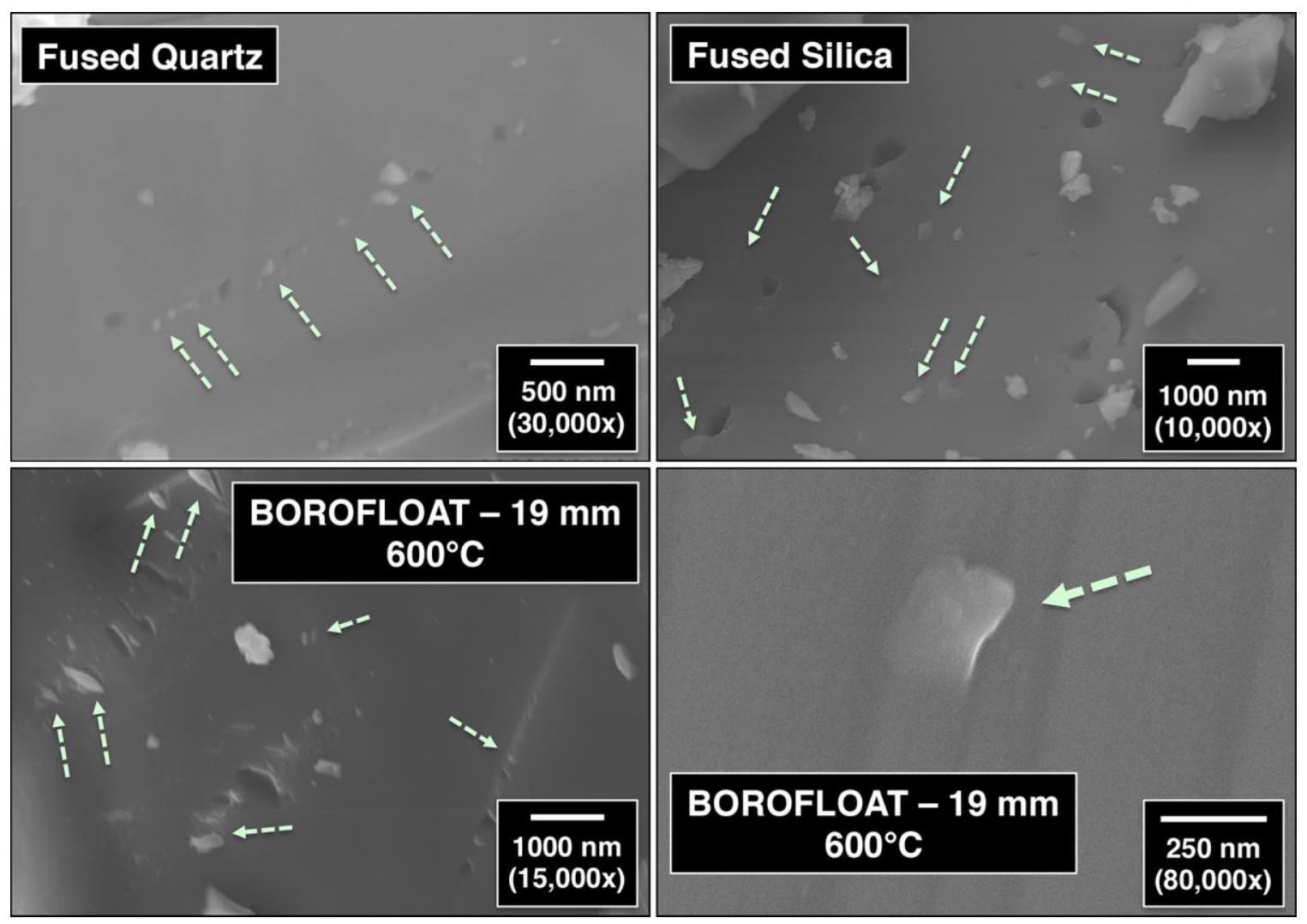

Figure 10. Examples of still-surface-adhered microkernels. It is believed that the shown micropores are microkernels that existed but were ejected during the overall fracture event. The top two images were taken with fragments generated at room temperature and bottom two were from hot impact tests. 


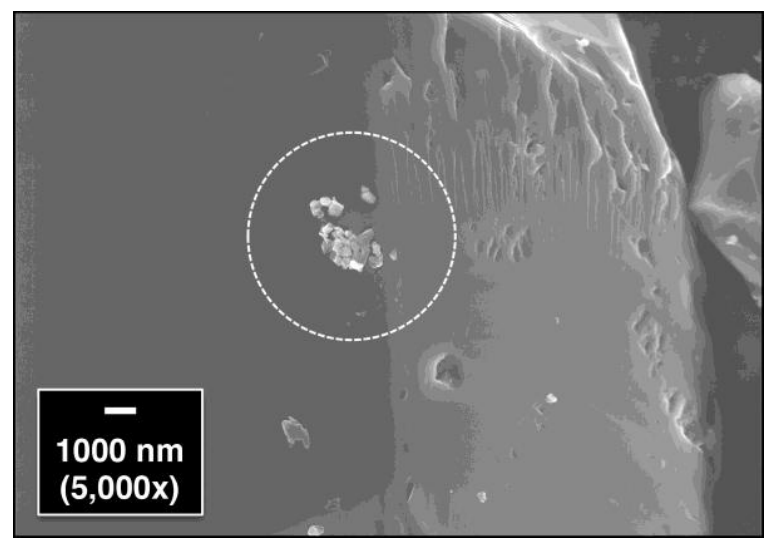

Figure 11. Example of a deposited pile of microkernels after ultrasonic cleaning. They are brighter because of SEM-induced electrical charging.

The sub-micron microfractures often had a planar or porous-seam habit to them. An obvious illustration of that would be if there were many of them spatially located on a fracture surface (plane) or spatially located on the surfaces of two intersecting fracture surfaces; however, they were sometimes concentrated along seams that intersected the fracture surface. Examples of this observation are shown in Fig. 12.

Lastly, fragments of silica-based glasses, generated from two other methods imposing high-strain-energies, were similarly sieved and examined. A double-toroid diamond anvil cell (DTDAC) was used to hydrostatically load a Borofloat sample (of the shape of a conventional baby aspirin with a volume of $31 \mathrm{~mm}^{3}$ ) up to $15 \mathrm{GPa}$, and a ballistic test was used to generate fragments with another borosilicate glass. Sub-micron microfractures were also observed on their fragments and examples of such are shown in Fig. 13. 

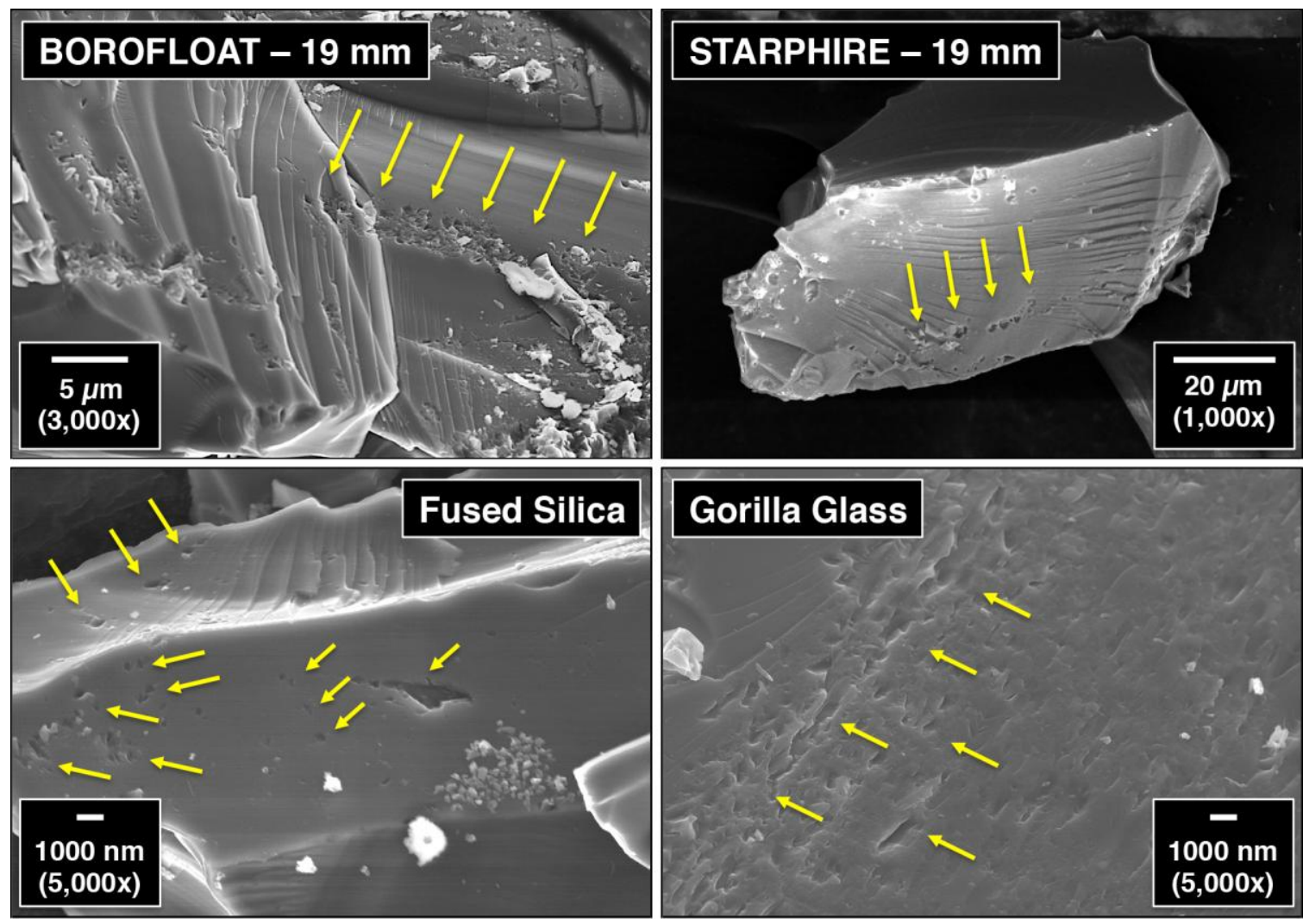

Figure 12. Examples of the sub-micron microfractures having a planar or porous seam habit.
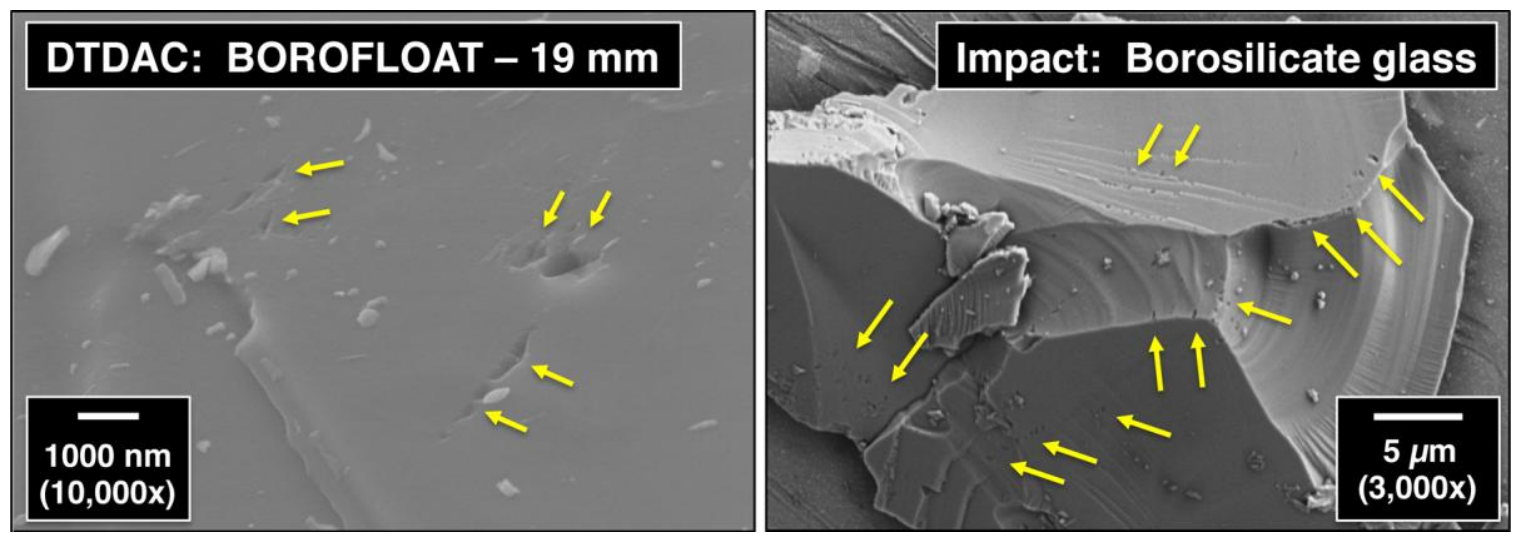

Figure 13. Examples of sub-micron microfractures on the surfaces of fragments that were generated by a different manner of high-strain-energy loading. A double toroid diamond anvil cell (DTDAC) was used to load Borofloat to 15 GPa, and another borosilicate glass was subjected to a ballistic test and its fragments studied. 


\section{Discussion}

\subsection{Fragmentation}

The fracture and fragmentation chronology becomes quite complex immediately after impact. That is true even with a simple test specimen geometry like a cylinder that is uniaxially compressed. The impact-generated longitudinal shock wave speed is $\sim 5000 \mathrm{~m} / \mathrm{s}$ for silica-based glasses so it takes $\sim 2 \mu \mathrm{s}$ for the wave to travel the length of a 10-mm-tall specimen. Contrast that with the terminal crack propagation speed of $\sim 1900 \mathrm{~m} / \mathrm{s}$ within these silica-based glasses whereby a crack can travel about $~ 3-4 \mathrm{~mm}$ in that same amount time, and it becomes evident that the cracking occurs in the wake of the traveling shock wave. Once shock tensile-stress rarefactions begin to (nearly immediately) occur, then additional fracture initiations, secondary fracturing, and interparticle-comminution become convoluted during the fracture event. The generated fragments, such as those shown in Fig. 3(c)-(d), are a record of the complete history of that very complex event.

The smaller particles of the generated fragment distribution were primarily examined because it was believed that their greater amounts of exposed surface area (per volume) would provide a greater likelihood of exposing the microkernels and perhaps evidence of failure initiation from them.

Regarding size itself, three independent models (Griffith criterion [2], fragmentation behavior under dynamic impact [5], and comminution theory [6]) all have the same form of

$$
d \mu \frac{K_{I c}^{2}}{S_{T e n}^{2}}
$$

where $d$ is a size or length scale, $K_{I c}$ is Mode I fracture toughness, and $S_{T e n}$ is locally applied tensile stress. The loading conditions are multiaxial $\left(K_{I}, K_{I I}\right.$, and $\left.K_{I I I}\right)$ and fracture would likely be controlled by tensile stresses in the opening mode (Mode I) because $K_{I C}$ has the lowest value of the three. The $K_{I c}$ of silica-based glasses is less than $\sim 1 \mathrm{MPa} \sqrt{ } \mathrm{m}$ [7], and the applied 
(rarefaction-induced, comminution-induced, and shear-induced) $S_{T e n}$ under high-strain-energy can be large. Therefore, the anticipated (fragment) $d$ should be correspondingly small. Secondary fracturing, caused by the destructive action of the tensile elastic strain wave created during the first fracture, has been recognized as a mechanism for over 50 years [8], is likely ubiquitous throughout the fracture history under such initially-applied, high-compressive-strain loading, and contributes to the comminution process. While examinations conclusively and repeatedly showed evidence of sub-micron-sized kernels and their mating pores on these small fragments, no fractographic evidence was observed to show that local fracture initiation was caused by their presence.

The qualitative identification of sub-micron microfractures in various silica-based glasses was the primary objective of this study, so the maximum size of "small fragments" for examination was somewhat arbitrarily chosen as $63 \mu \mathrm{m}$ (i.e., fragments passing through a 230 mesh sieve). But larger fragments that did not pass through this sieve size sometimes did have these sub-micron microfractures on them - but many fragments needed to be examined before one was found to possess them (these larger fragments had undergone permanent densification as will be discussed in Section 3.2, and that is an important condition in context to some microfractures being present on them). As a comparison, the fracture surfaces of fragments generated from lower-strain-energy fracture (e.g., fracture from a flexure type test) showed no evidence of these sub-micron microfractures on their fracture surfaces. The high-strain-energy fracture of these silica-based glasses, and the to-be-discussed permanent densification that consequentially occurred, appears to be a prerequisite for the exposure or generation of these sub-micron microfractures.

The fragmentation of silica-based glasses under high-strain energies has been studied for decades with focus primarily devoted to the interpretation of resulting particle size distribution and the energies associated with their formation. Bergstrom [9] and Gilvarry [10] quasistatically compressed silica-based glass spheres - a geometry and test that can impose a high strain up to the moment of fracture. However, Hertzian contact effects (elastic property mismatch and friction [11]) at the two opposed loading locations (prematurely) affect failure initiation and thus "downstream fracture" too, the strain field in a loaded sphere is not uniform, 
so non-equiaxed fragment shapes, such as lunes [10] can consequentially form. No lune-shape fragments were observed in all the present study's fragment examinations presumably because they came from uniaxially compressed cylindrical samples that were impacted with a larger diameter drop-weight. But the quantification of the generated particle size distribution was not an objective in this study - just the surface-morphology study of the smaller fragments in that distribution.

Fragmentation under dynamic loading conditions (i.e., another high-strain-energy failure event) have been studied for decades with devotion also made to the generated fragment size distribution (e.g., starting with Grady [4] and Glenn and Chudnovsky [12]) . Microstructural examination of the surfaces of those fragments evidently were not pursued, but if they were, the authors of this present study speculate that sub-micron microfractures would have been present if permanent densification had been produced as a consequence of their employed loadings.

It is more difficult to generate such small-sized fragments with conventional quasi-static (slow-loading-rate) compressive loading. This is because surface and edge flaws on the surfaces of silicate-based glass samples, coupled with end-platen-loading irregularities, elastic property mismatch and friction between platen and specimen, end up inducing fracture initiation at low stress or strain (i.e., stored strain-energy at fracture initiation is relatively low). There is insignificant concomitant shock to superimpose local tensile stresses (and potential consequential secondary fracturing) and contribute to the overall crushing response. Low stored energy at fracture does not provide a strong driving force for crack branching or formation of many fragments [4]. It was for these reasons that high-strain-energy imposition via drop-weight loading was pursued in this present study. 


\subsection{Densification}

Potential changes in density due to the drop-weight were qualitatively examined using the float method with a high-specific-gravity liquid. Lithium metatungstate, a commercially available liquid whose specific gravity (SG) is 2.95, and which is aqueous-based, was diluted with water to custom produce lower SG's that matched the density of the silica-based glasses. Untested material and produced fragments were purposely co-placed in the fluid. If densification had occurred in the silica-based glasses' produced fragments, then the fragments would float at a lower height than the untested material. Any potential density changes in the magnesium fluoride and sapphire could not be examined with this lithium metatungstate because their densities are greater than its starting SG.

The employed impact test conditions caused the silica-based glasses to permanently densify. Such was identified using controlled specific gravity liquids and observation of floating, suspension, and settling of untested and tested silica-based glasses, and is illustrated in Fig. 14. All the generated particles, including those that did not pass through the $63-\mu \mathrm{m}$ sieve (which are likely the particles that are visible in Fig. 14), were co-placed with the untested samples. The higher-density fragments were also the fragments that possessed microkernels on their surfaces; this indicates that the onset of permanent densification is correlated with the exposure or formation of the microkernels, or perhaps a prerequisite for their exposure or generation. 
Fused Quartz

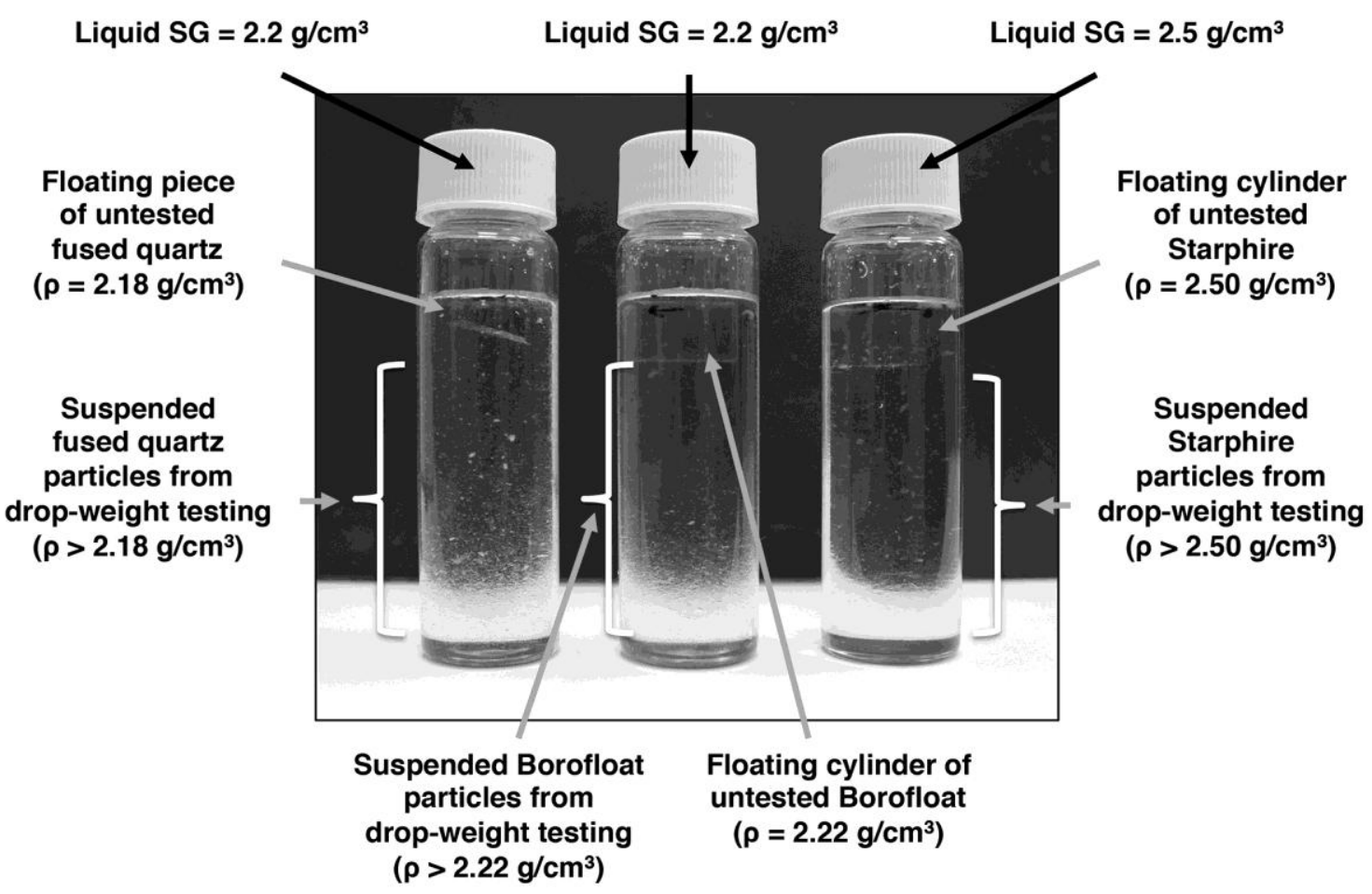

Figure 14. Floating cylinders of untested glass co-located with higher-density fragments resulting from the drop-weight testing.

The recognition of the ability to densify silica-based glasses has existed since Bridgeman's work from the late 1940s [13] and an abundant amount of literature has been generated since on this subject, including the greater ease of its occurrence in the presence of shear [14-15]. Therefore, that densification occurred in this testing is not special; however, that the herein-described sub-micron fracture mechanism associated with it appears to be discussed for the first time - this is indeed noteworthy.

The densified silica-based glasses in Fig. 14 are examples of what have been previously designated as "normal" and "anomalous" glasses in reference to indentation-induced differences in deformation and fracture responses [16]. The deformation of "normal" glasses is viewed by being shear-dominated flow or reconstructive process whereas "anomalous" glasses deform from a pressure-dominated densification or displacive process. No matter the process, the imposed 
high-strain in the present study's testing was sufficient to cause densification in both "normal" and "anomalous" glasses.

Differences in the apparent concentration of microkernels for at least two of the silicabased glasses (shown in Table I) may be correlated to apparent yield stress. The apparent yield stress of several of these silica-based glasses was measured by one of the authors $[7,17]$ using spherical indentation (a test that produces a combination of hydrostatic and shear loading). The Borofloat glass had an apparent yield stress that was approximately $25 \%$ lower than that for the Starphire glass. In context to the microkernel concentrations, this suggests that the Borofloat would start to densify at a lower force (or stress or strain) than the Starphire, or if the applied strain was sufficiently high to initiate densification in both, then the Borofloat would accumulate more (permanent) plastic-like deformation for that applied strain. Such a supposition would be consistent with the Borofloat having a higher concentration of the microkernels than the Starphire.

\subsection{Sub-Micron Kernels and Pores}

Sub-micron microfractures, consisting of microkernels or mating micropores, were consistently revealed or produced from the high-strain-energy fracture imposed on all the tested silica-based glasses. The authors contend their exposure or generation is associated to the onset of loading-induced permanent densification. Their sizes ranged from 300 to $\sim 1000 \mathrm{~nm}$; this is a range that is consistent with what was observed in the shock testing described in Figs 1-2. If the microkernel had popped out when the fracture plane went though it or as a consequence of localized shock rarefaction in the fragment, then it would appear as a surface-located pore.

A rough estimate was made of the concentration of the sub-micron microfractures should the microkernels be pre-existing. About 100 microfractures on the surface of one $\sim 50-\mu \mathrm{m}$ fragment of Borofloat were counted. The fragment shape was estimated to have a size that was about $1 / 3$ of a $50-\mu \mathrm{m}$ cube, which is a volume of $4 \times 10^{-8} \mathrm{~cm}^{3}$, and that is a microkernel concentration of about $10^{9} / \mathrm{cm}^{3}$. 
The sub-micron heterogeneity in these materials (i.e., what manifests itself into the observed microkernel), is argued to exist in all these silica-based glasses [18-20], must have some dissimilarity in its composition compared to its surrounding matrix material. The chemistry of several microkernels were compared with that of the surrounding material, and no conclusive differences were observed (at least within the $\sim 0.1 \%$ resolution of our FE-SEM's Energy Dispersive X-ray Spectrometer). But minor differences in chemical composition could manifest the microkernels having a slight dissimilarity in density, elastic modulus, Poisson's ratio, and coefficient of thermal expansion. Such a hypothetical situation could also cause local residual stresses in and around the microkernel if they were not relieved during the processing of the silica-based glasses. In any of these scenarios, the local shock wave encountering the microkernel has the potential to be perturbed by it, create conditions for tensile stresses even under compressive loading, with the result that terminal fracture can occur through it and potentially eject the microkernel. If these microkernels are indeed indigenous, then the authors speculate these effects could be operative.

Shear transformation zones, which are regularly discussed in the literature for bulk metallic glasses [21] have not been sincerely explored yet for silica-based glasses. Obviously the metallic bond is quite different than the covalent bonding in silica-based glasses so an analog may be not be operative in the latter. However, it is warranted that the observed microkernels here, perhaps associated with a heterogeneous precursor state, be interpreted as a possible consequence of localized shear transformation associated with the observed permanent densification and shock.

Sub-micron microfractures in synthetic single-crystal alpha-quartz are an indication that similar sub-micron heterogeneities exist in it analogous to those that are apparently in the silicabased glasses. The as-received purity and concentration of sub-micron heterogeneities were unknowns; however, the presence of the latter is indicated by microkernel and micropores on some of its fragments. 
The equivalence of the size range of the microkernels and micropores for all the silicabased glasses and synthetic alpha-quartz draws attention to what is common among their materials. They all have elastic moduli, densities, Poisson's ratios, and fracture toughnesses that are relatively equivalent so shock speed is similar in all as is the terminal crack propagation speeds within them. All are made by processes where small-sized heterogeneities (those represented by localized compositional differences or intrinsic flaws) could and do result. The authors speculate that these similarities are what contributes to the exposed or created size range of the microkernels or micropores in the silica-based glasses and synthetic alpha-quartz.

The generated fragments from the non-silicate materials tested, single crystal magnesium fluoride and single crystal sapphire, showed no evidence of microkernels nor micropores. Compared to all the silicates, the elastic moduli, Poisson's ratio, and densities are higher for magnesium fluoride and sapphire, and the impact strain in them was lower. They also have ordered crystal structures with anisotropic mechanical properties. The apparent yield stress in single crystal magnesium fluoride and single crystal sapphire are likely higher than it for the silica-based glasses too. The authors speculate that some combination of those differences, with the possibility that the intrinsic tensile strength in single crystal magnesium fluoride and sapphire, and the stress where they begin to yield, are higher than that for silica-based glasses and crystalline alpha-quartz. Note that intrinsic strength is not a material property; namely, intrinsic flaws limit that strength, may not always be homogeneously sized in all fabricated billets or batches of the "same material", and therefore would produce different intrinsic strengths for the "same material". Because of this complexity, the authors can only conclude that no microkernels or micropores, like those observed in the silica-based glasses and single crystal alpha-quartz, formed under identical drop-weight impact loading of these two non-silicate materials.

Increased temperature during high-strain-energy fracture tended to cause the fragments to have still-bonded microkernels on them whereas they mostly appeared as micropores when the testing was at room temperature. The samples were in an opaque container during their testing so their temperature could not be measured using infrared imaging; however, due to the short time of transfer from the $600^{\circ} \mathrm{C}$-furnace to the tester, the sample's average temperature was 
likely greater than $400^{\circ} \mathrm{C}$. Depending on dilatometry heating rate, the estimated glass transition temperature, $\mathrm{Tg}$, of the Borofloat was $540-570^{\circ} \mathrm{C}$ and that for the Starphire $580-610^{\circ} \mathrm{C}$ [7], so impact was likely below $T g$ of both materials. The ease of microkernel ejection appears to be more difficult when the two silica-based glasses were tested at high temperature which, if true, indicates that the adhesive bond strength of the microkernel with its surround matrix is higher at higher temperatures.

Several methods that cause high-strain-energy fracture generated similarly-sized microkernels and micropores in silica-based glasses. They included the drop-weight testing, but also hydrostatic loading using a double-toroid diamond anvil cell (DTDAC), and ballistic impact. The former two, because of their relatively slow rate of loading or impact, were quasi-static whereas the latter superimposed dynamic loading. The existence of high strain-energy (and associated densification) at fracture was common to all so superimposed dynamic loading (such as that in a ballistic impact) is not a prerequisite to expose these microkernels and micropores in these silica-based glasses. The application of a sufficiently high compressive strain to cause permanent densification $i s$ the prerequisite.

The size-range of these interior pores is several orders of magnitude smaller than surfacelocated flaw sizes (tens to hundreds of microns) that typically limit flexure strength of common silicate glasses, so high-strain-energy (such as that caused in ballistics and shock, and that that can cause densification), and the associated high tensile stress that it can apply, appears to be a prerequisite for this "microkernel fracture mechanism" to be operative in the fracture of these silica-based glasses.

A simple visual test can illustrate the presence of heterogeneities in the silica-based glasses. A Tyndall test, done with a green laser transmitted through the silica-based glasses, visibly showed the laser beam within it. This is illustrated in Fig. 15. Submicroscopic heterogeneities (e.g., precursors to the exposed or generated microkernels) can be detected by the light scattered by them. It cannot be concluded yet that the microkernels observed on the fragments generated from high-strain-energy are responsible for such light scattering; however, it can be concluded that something in these glasses is causing that scattering. The present study's 
authors speculate that these microkernels, or their precursor-state, contribute to that scattering, and therefore, are indigenous to the glass.

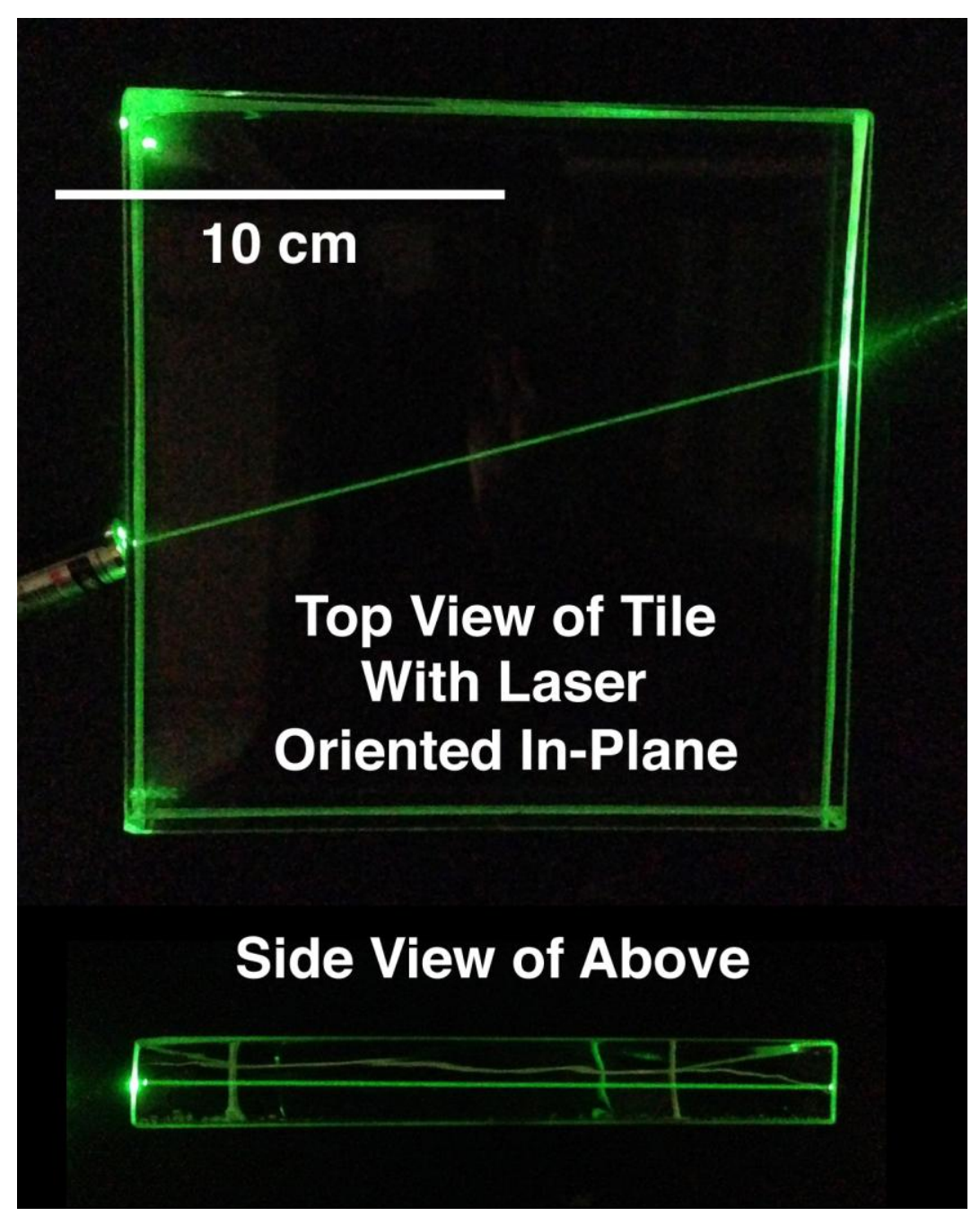

Figure 15. Tyndall Effect using green laser light (532 $\mathrm{nm})$ and showing internal scattering throughout a $1.9 \times 15 \times 15 \mathrm{~mm}$ Borosilicate glass tile. Laser source at left in both images.

Evidence of indigenous microkernels was sought using optical microscopy with sectioned and polished Borofloat. No heterogeneities at that scale were identifiable. But if the calculated concentration of $10^{9} / \mathrm{cm}^{3}$ is representative, then the statistical likelihood that a sectioned/polished plane went through any one of the microkernels is nearly zero, so given they were not 
identifiable does not mean they were not there. High-energy fracture ends up being an effective way to show them - analogous to the effective way to expose creep cavitation by interrupting a high-temperature creep test and fracturing the specimen at room temperature [22]. The source or any precursor-state of the microkernels, if indeed indigenous, is not yet known and identification of such will be a subject of future work by the authors.

Spall fracture can occur in materials after a compressive shock wave has rarefacted from a free surface and the tensile stress exceeds the material's intrinsic tensile strength [23]. Examples and analysis of such spalling can be found in previous work by one of the authors involving polycrystalline ceramics [24]. Unlike that which is described in Ref. [22], the primary (larger) lateral crack shown in Fig. 1 is not a spall crack because it initiated from the tensile wave trailing the compressive wave (i.e., it formed before rarefaction occurred at the back surface) [1]. But regardless of the mechanism of how a high tensile stress is generated, and due to the dynamic nature associated with the complete generation of the fragment population in any of the presently described tests, and recognition that secondary fractures can occur due to rarefaction [8], might the exposure (or creation) of the microkernels, and their ejection to portray the presence of a mating micropore, be a form of spallation? The authors continue to explore this as a possible mechanism.

\subsection{Planar Habit and Crack Branching}

These microkernels do not appear to be homogeneously distributed, often were locally concentrated, and sometimes had a planar habit to their positioning. Some of the explored silicabased glasses in this study are known to have straie [6]. Striae are a mesoscale heterogeneity whose existence is a consequence of incomplete mixing of the melt prior to solidification. They are exposable with visible light because of their slight, multilaminar variations in index of refraction. Examples of these straie are shown in Fig. 16. Heterogeneities in some glasses have been correlated to straie patterns [25]. The present study's authors speculate that these microkernels (or their precursors) could be contributing to the striae patterns by their sometimesexisting planar habit shown in Fig. 11, and perhaps could have influenced the depth of where the lateral crack had formed in the sample shown in Fig. 1. 


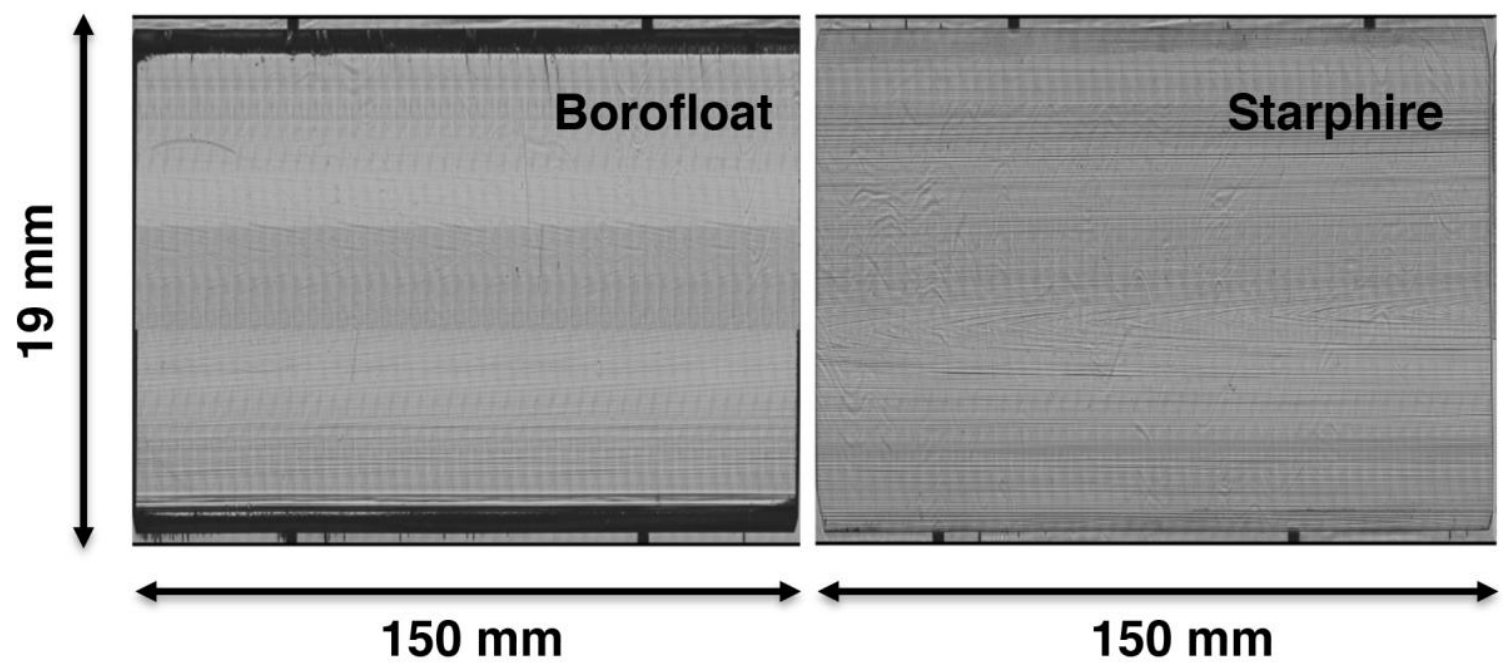

Figure 16. Examples of straie in two of the studied silica-based glasses. The thickness direction $(19 \mathrm{~mm})$ is skewed so to better show the striae which are mostly horizontal, convention-like patterns and faint, parallel lines.

No evidence of fracture mirrors were found adjacent to the microkernels which suggests they were not associated with local failure initiation or that it is statistically unrealistic to find them when there are so many fracture surfaces generated in events such as these tests. However, their very presence on fracture surfaces, and often at edges of crack bifurcations (Fig. 2) and intersecting fracture surfaces (Fig. 11), suggests they sometimes influenced the secondary fracture process, where the fracture boundaries of some fragments ultimately formed, and the overall crushing and comminution response of these silica-based glasses at these high strain energies. These events are schematically illustrated in Fig. 17(a)-(f). The microkernels (or their precursors) are subjected to sufficiently high compressive and shear strain that causes permanent densification, and then elastic tensile strain release upon unloading and local cracking can expose them as a crack plane path of least resistance, Fig. 17(e), or crack plane deflection, Fig. 17(f). Most of the above images are represented by Fig. 17(e), whereas the crack deflection in Fig. 2(d) is represented by Fig. 17(f). 


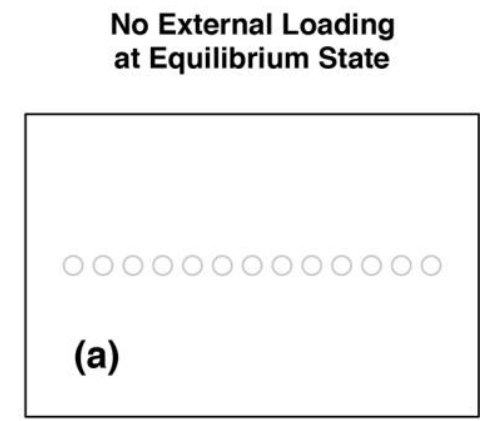

Rapid (Elastic) Unloading

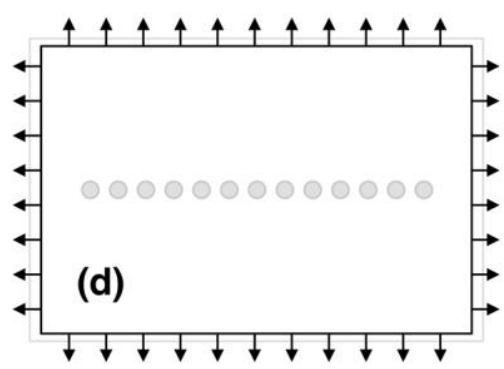

Hydrostatic Compression \& Permanent Densification

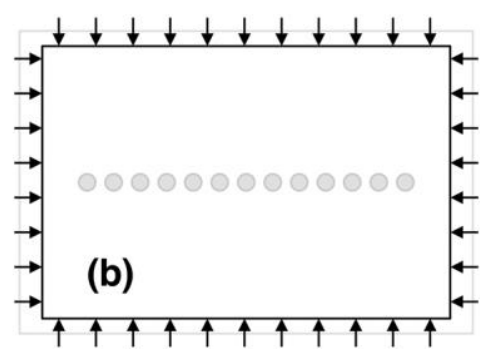

Crack Propagation

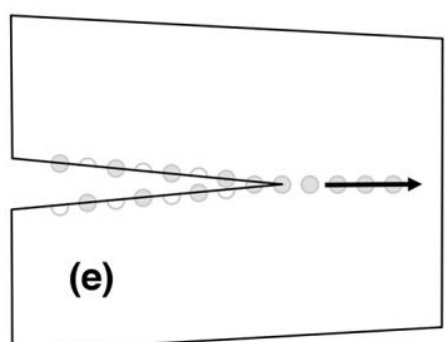

Hydrostatic Compression + Shear \& Permanent Densification

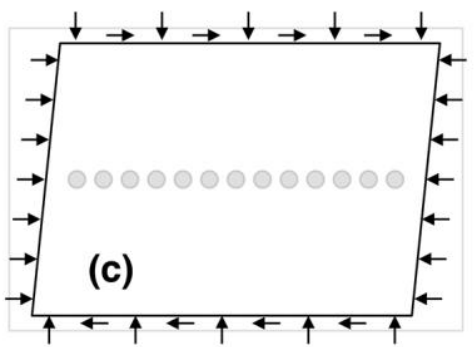

Crack Deflection

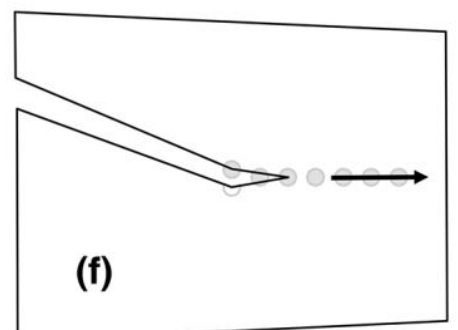

Figure 17. Schematics of (a) a planar array of indigenous microheterogeneities in the silica-based glasses, the overall densification brought on by (b) hydrostatic loading and (c) concurrent shear, (d) rapid elastic loading, and examples of resulting (e) crack propagation, and $(f)$ crack deflection associated with the just-occurred densification and presence of the microheterogeneities.

\subsection{Absence of Previous Observations}

There is a combination of at least three likely reasons why the herein-described submicron-sized kernels and pores have not been previously described in the literature.

Producers and end-users in the silica-based glass community almost entirely use their materials in structural applications where high-strain is never imposed or fracture occurs at relatively low strains - namely - only at tenths of one percent (e.g., fracture due to bending). Management of the relatively large (e.g., hundreds of microns), surface-located, strength-limiting flaws are of the greatest importance to their community. If permanent densification is indeed a 
prerequisite for the exposure or generation of the sub-micron-sized kernels and pores, then they would not be expected to activate (and therefore identified) in nearly all applications of these silica-based glasses.

If there indeed is an indigenous precursor state of these microkernels and micropores in these silica-based glasses, then they are of a size $(\sim 300-1000 \mathrm{~nm})$ and concentration $\left(10^{9} / \mathrm{cm}^{3}\right.$ estimated) that apparently do not detrimentally affect optical transparency nor limit the structural potential for nearly all (or all) its structural and common applications. Therefore, if their dormant, precursor state is not a performance limiting issue, then there is not an impetus for the glass community to address them.

Silica-based glasses have been tested by the ballistics and armor community for many years. There is an ample amount of literature on their fragmentation, its produced sizedistribution, and modeling of the energetics of such. However, no literature was found where their authors also described the microstructural habit of those fragments at high magnifications. If any of those studies had caused permanent densifications of their examined silica-based glasses then the sub-micron-sized kernels and pores described in the herein study were likely present on the fragments in those studies but were not identified.

\section{Conclusions}

Sub-micron-sized fractures, or microkernels, occurring within several silica-based glasses were consistently revealed or produced from high-strain loading sufficient to cause permanent densification. These microkernels ranged in size from $\sim 300-1000 \mathrm{~nm}$ and appeared on the surfaces of fragments. If the microkernel had popped out when the fracture plane went though it or as a consequence of localized shock rarefaction in the fragment, then it would appear as a surface-located pore.

These microkernels do not appear to be homogeneously distributed, often were locally concentrated, and sometimes had a planar habit to their positioning. The very presence of these sub-micron features on fragment surfaces, and often at the edge where a crack bifurcation had 
occurred, and on intersecting fracturing surfaces, suggests they could have influenced (1) the secondary fracture process, (2) where the fracture boundaries of some fragments ultimately formed, and (3) the overall crushing and comminution response of these silica-based glasses if permanent densification had occurred as a consequence of the mechanical loading. However, no evidence of fracture mirrors were found adjacent to the microkernels so it cannot be concluded yet they were associated local fracture initiation.

The size-range of these interior pores is several orders of magnitude smaller than surfacelocated flaw sizes (tens to hundreds of microns) that typically limit glass flexure strength, so permanent densification from high-strain-loading (such as that potentially caused in ballistics

and shock) appears to be a prerequisite for this "microkernel fracture mechanism" to be activated in the fracture of these silica-based glasses.

\section{Acknowledgments}

The authors thank T. Talladay, A. Dolan, and D. Templeton (retired) of the US Army Tank-Automotive Research, Development and Engineering Center (TARDEC), W. Chen of Purdue University, and P. Patel of the US Army Research Laboratory (USARL) for their support of this work, and the latter for also supplying some of the materials for this testing. Gratitude is extended to P. Patel and J. Swab of USARL, T. Holmquist of SWRI, G. Quinn (retired) of NIST, M. Davis of Schott Glass, N. Borelli and T. Seward (retired) of Corning Glass, A. Moreira Dos Santos, M. Ferber (deceased), and P. Becher (retired) of ORNL, and D. Grady of ARA for their helpful insights, and ORNL's E. Lara-Curzio, H. Wang, and J. -A. Wang for their reviews.

Disclaimer: Reference herein to any specific commercial company, product, process, or service by trade name, trademark, manufacturer, or otherwise, does not necessarily constitute or imply its endorsement, recommendation, or favoring by the United States Government or the Department of the Army (DoA). The opinions of the authors expressed herein do not necessarily state or reflect those of the United States Government or the DoA, and shall not be used for advertising or product endorsement purposes. 


\section{References}

[1] T. J. Holmquist and A. A. Wereszczak, "The Internal Tensile Strength of a Borosilicate Glass Determined from Laser Shock Experiments and Computational Analysis," International Journal of Applied Glass Science, 5:345-352 (2014).

[2] A. A. Griffith, "The Phenomena of Rupture and Flow in Solids," Philosophical Transactions of the Royal Society of London. Series A, 221:163-198 (1921).

[3] "Standard Practice for Fractography and Characterization of Fracture Origins in Advanced Ceramics,” ASTM C1322. Vol. 15.01, ASTM International, West Conshohocken, PA, 2002.

[4] G. D. Quinn, Fractography of Ceramics and Glasses, NIST Recommended Practice Guide, Special Publication 960-16, 2007.

[5] D. E. Grady, "Local Inertial Effects in Dynamic Fragmentation,” Journal of Applied Physics, 53:322-325 (1982)

[6] J. S. Reed, Introduction to the Principles of Ceramic Processing, Chapter 16, John Wiley \& Sons, New York, 1988.

[7] A. A. Wereszczak and C. E. Anderson, Jr., "Borofloat and Starphire: A Comparison," International Journal of Applied Glass Science, 5:334-344 (2014).

[8] J. Miklowitz, "Elastic Waves Created During Tensile Fracture, The Phenomenon of a Second Fracture," Journal of Applied Physics, 20:122-130 (1953).

[9] B. H. Bergstrom, C. L. Sollenberger, and W. Mitchell, Jr., "Energy Aspects of Single Particle Crushing," Transactions of the American Institute of Mining, Metallurgical, and Petroleum Engineers, 220:367-372 (1961).

[10] J. J. Gilvarry and B. H. Bergstrom, "Fracture of Brittle Solids. II. Distribution Function for Fragment Size in Single Fracture (Experimental)," Journal of Applied Physics, 32:400410 (1961).

[11] A. A. Wereszczak, W. L. Daloz, K. T. Strong, Jr., and O. M. Jadaan, "Effect of Indenter Elastic Modulus on Hertzian Ring Crack Initiation in Silicon Carbide," International Journal of Applied Ceramic Technology, 8:885-894 (2011).

[12] L. A. Glenn and A. Chudnovsky, "Strain-Energy Effects on Dynamic Fragmentation," Journal of Applied Physics, 59:1379-1380 (1986). 
[13] P. W. Bridgman, “The Compression of 39 Substances to 100,000 kg/cm²," Proceedings of the American Academy of Arts and Sciences, 76:55-70 (1948).

[14] H. M. Cohen and R. Roy, "Reply to 'Comments on Effects of Ultrahigh Pressures on Glass,," Journal of the American Ceramic Society, 45:398-399 (1962).

[15] J. D. Mackenzie, "High-Pressure Effects on Oxide Glasses: I, Densification in Rigid State," Journal of the American Ceramic Society, 46:461-470 (1963).

[16] A. Arora, D. B. Marshall, B. R. Lawn, "Indentation Deformation/Fracture of Normal and Anomalous Glasses," Journal of Non-Crystalline Solids, 31:415-428 (1979).

[17] A. A. Wereszczak, T. G. Morrissey, M. K. Ferber, K. P. Bortle, E. A. Rodgers, G. Tsoi, J. M. Montgomery, Y. Vohra, and S. Toller, "Responses of Siliceous Materials to High Pressure," Ceramic Engineering and Science Proceedings, 34 [5] Paper 04-01 (2013).

[18] E. A. Porai-Koshits, "Structure of Glass: The Struggle of Ideas and Prospects," Journal of Non-Crystalline Solids, 73:79-89 (1985).

[19] A. C. Wright, "The Great Crystallite Versus Random Network Controversy: A Personal Perspective," International Journal of Applied Glass Science, 5:31-56 (2014).

[20] T. Deschamps, C. Martinet, D. R. Neuville, D. de Ligny, C. Coussa-Simon, and B. Champagnon, "Silica Under Hydrostatic Pressure: A Non Continuous Medium Behavior," Journal of Non-Crystalline Solids, 355:2422-2424 (2009).

[21] L. Berthier and M. D. Ediger, "Facets of Glass Physics," Physics Today, [1] 69:40-46 (2016).

[22] M. K. Ferber and M. G. Jenkins, "Evaluation of the Strength and Creep-Fatigue Behavior of a HIPed Silicon Nitride," Journal of the American Ceramic Society, 75:2453-2462 (1992).

[23] M. A. Myers, Dynamic Behavior of Materials, John Wiley \& Sons, New York, NY, 1994.

[24] T. J. Holmquist and A. A. Wereszczak, "Laser Induced Spall in Silicon Carbide,” pp. 9971004 in Proceedings of the $23^{\text {rd }}$ International Symposium on Ballistics, Eds. F. Gálvez and V. Sánchez-Gálvez, Tarragona, Spain, April 16-20, 2007.

[25] M. Jensen, R. Keding, S. Fjendbo, H. H. Poschwatta, and Y. Yue, "Effect of Bubbles on the Characterization of Straie in Glasses," Glass Technology - European Journal of Glass Science and Technology Part A, 51:147-152 (2010). 